\title{
PEMOGRAMAN JAVA RUMAH SAKIT
}

NPM $\quad: 19421034$

Nama : Novanka Fadilla Azhari Huzien

Prodi : Informatika

Fakultas : Fakultas Ilmu Komputer

Email : novanka.fadilla@gmail.com

\section{SOAL TUGAS :}

1. Buatlah Program dengan ketentuan sebagai berikut :

Input :

kode pasien $=$ PS0003

Kode Kamar $=\mathbf{4 4 4 4 4}$

Lama Menginap $=5$ hari

Kode Dokter $=$ DK003

\begin{tabular}{|l|l|l|}
\hline Kode Pasien & Status Pasien & Biaya Daftar Pasien \\
\hline PS0001 & Pasien Baru & Rp. 500.000 \\
\hline PS0002 & Pasien Lama & Rp. 400.000 \\
\hline PS0003 & Pasien BPJS & Rp. 300.000 \\
\hline PS0004 & Pasien Askes & Rp. 200.000 \\
\hline
\end{tabular}

\begin{tabular}{|l|l|l|}
\hline Kode Kamar & Nama Kamar & Biaya Kamar \\
\hline 1111 & Kamar Melati & Rp. 1.000 .000 \\
\hline 2222 & Kamar Mawar & Rp. 2.000 .000 \\
\hline 3333 & Kamar Dahlia & Rp. 3.000 .000 \\
\hline 4444 & Kamar Anggrek & Rp. 4.000 .000 \\
\hline 5555 & Kamar Tulip & Rp. 5.000.000 \\
\hline
\end{tabular}

\begin{tabular}{|l|l|l|}
\hline Kode Dokter & Nama Dokter & Biaya Pemeriksaan \\
\hline DK001 & DR. Andi & Rp. 500.000 \\
\hline DK002 & DR. Joko & Rp. 400.000 \\
\hline DK003 & DR. Karni & Rp. 300.000 \\
\hline DK004 & DR. Amin & Rp. 200.000 \\
\hline DK005 & DR. Udin & Rp. 100.000 \\
\hline
\end{tabular}

\begin{tabular}{|l|l|}
\hline Lama Menginap & Diskon \\
\hline$>10$ Hari & $50 \%$ dari Biaya Kamar \\
\hline$>8$ Hari & $40 \%$ dari Biaya Kamar \\
\hline$>6$ Hari & $30 \%$ dari Biaya Kamar \\
\hline$>4$ Hari & $20 \%$ dari Biaya Kamar \\
\hline$>+1$ & $10 \%$ dari Biaya Kamar \\
\hline
\end{tabular}

Total Bayar = Biaya Daftar Pasien + Biaya Kamar + Biaya Pemeriksaan - Diskon

Output (Tampilkan) $=$

Status Pasien

Biaya daftar Pasien

Nama Kamar

Biaya Kamar

Nama Dokter

Biaya Pemeriksaan

Diskon 
Total Bayar

\section{SOURCE CODE / KODING PROGRAM (KETIK DIBAWAH INI)}

public class rumahsakit\{

public static void main (String []args)\{

String kodePasien = "PS00003";

String namaKamar;

String statusPasien;

double lamaMenginap = 1;

String kodeDokter = "DK003";

String namaDokter;

double biayaPemeriksaan;

double biayaDaftar;

double biayaKamar;

double kodeKamar = 4444;

double diskon;

double totalBayar;

if(kodePasien=="PS0001")\{

statusPasien = "pasienbaru";

biayaDaftar = 500000;

\}else if(kodePasien=="PS0002")\{

statusPasien = "pasienlama";

biayaDaftar $=400000$;

\}else if(kodePasien=="PS0003")\{

statusPasien = "pasienBPJS";

biayaDaftar = 300000;

\}else\{

statusPasien = "pasienaskes";

biayaDaftar = 200000;

\}

System.out.printIn("kode pasien ="+kodePasien);

System.out.printIn("status pasien ="+statusPasien); 
System.out.println("biaya daftar ="+biayaDaftar);

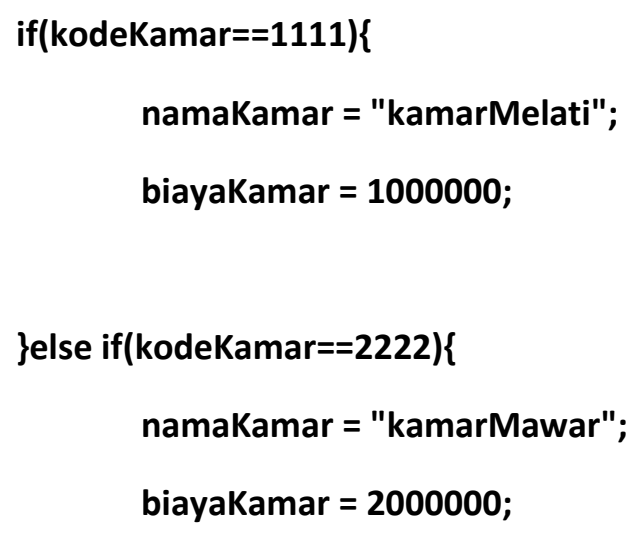

\}else if(kodeKamar==3333)\{

namaKamar = "kamarDahlia";

biayaKamar $=300000$;

\}else if(kodeKamar==4444)\{

namaKamar = "kamarAnggrek";

biayaKamar $=4000000$;

\}else\{

namaKamar = "kamarTulip";

biayaKamar = 5000000;

\}

System.out.println("kode kamar ="+kodeKamar);

System.out.printIn("nama kamar ="+namaKamar);

System.out.printIn("biaya kamar ="+biayaKamar);

if(kodeDokter=="DK001")\{

namaDokter = "DR. Andi";

biayaPemeriksaan = 500000;

\}else if(kodeDokter=="DK002")\{

namaDokter = "DR. Joko"; 
biayaPemeriksaan = 400000;

\}else if(kodeDokter=="DK003")\{
namaDokter = "DR. Karni";
biayaPemeriksaan = 300000

\}else if(kodeDokter=="DK004")\{

namaDokter = "DR. Amin";

biayaPemeriksaan = 200000;

\}else\{

namaDokter = "DR. Udin";

biayaPemeriksaan = 100000;

\}

System.out.println("kode dokter ="+kodeDokter);

System.out.printIn("nama dokter ="+namaDokter);

System.out.printIn("biaya pemeriksaan ="+biayaPemeriksaan);

if(lamaMenginap $>=10)\{$

diskon $=0.5 *$ biayaKamar;

\}else if(lamaMenginap $>=8)\{$

diskon $=0.4$ biayaKamar;

\}else if(lamaMenginap $>=6)\{$

diskon $=0.3 *$ biayaKamar;

\}else if(lamaMenginap $>=4)\{$

diskon $=0.2 *$ biayaKamar;

\}else\{

diskon = 0.1 ${ }^{*}$ biayaKamar; 
System.out.printIn("lama menginap ="+lamaMenginap);

System.out.println("diskon ="+diskon);

totalBayar = biayaDaftar + biayaKamar + biayaPemeriksaan - diskon;

System.out.printIn("total bayar ="+totalBayar);

\}

\} 


\section{PENJELASAN SOURCE CODE (KETIK DIBAWAH INI)}

1. Buat nama class untuk memulai coding program. ex : rumahsakit

2. Ketik " public static void main (String []args)\{ "untuk memanggil variabel class dan menjalankan pengetikan codingan program pada java.

3. Lalu masukkan variabel dan inputan yang diminta, (Dengan menggunakan tipe data yang sesuai dengan kebutuhan kita inginkan).

ex : String KodePasien = "PSO03";

int KodeKamar = 4444;

int LamaMenginap = 5;

String KodeDokter = "DK003";

4. Setelah inputan dimasukkan, lalu masukkan lagi variabel berikut hasil output yang nantinya akan diminta, (Tentunya harus menggunakan tipe data yang sesuai dengan kebutuhan kita inginkan).

ex : String kodePasien = "PS00003";

String namaKamar;

String statusPasien;

double lamaMenginap = 1;

String kodeDokter = "DK003";

String namaDokter;

double biayaPemeriksaan;

double biayaDaftar;

double biayaKamar;

double kodeKamar $=4444$;

double diskon;

double totalBayar;

5. Lalu, kita codingkanlah tabel-tabel diatas. (Namun, karena kondisi yang dibutuhkan juga lebih dari 2 kondisi, maka guanakanlah if dan else if , agar hasil outputnya sesuai dengan kebutuhan kita).

ex : if(kodePasien=="PS0001")\{

statusPasien = "pasienbaru";

biayaDaftar = 500000;

\}else if(kodePasien=="PSO002")\{ statusPasien = "pasienlama"; biayaDaftar = 400000;

\}else if(kodePasien=="PS0003")\{ statusPasien = "pasienBPJS"; biayaDaftar = 300000;

\}else\{

statusPasien = "pasienaskes";

biayaDaftar = 200000;

\}

System.out.println("kode pasien ="+kodePasien); System.out.println("status pasien ="+statusPasien); System.out.println("biaya daftar ="+biayaDaftar); 
6. Lalu setelah codingan tabel 1 selesai, kita codingkanlah lagi tabel 2 yang diatas. (Masih sama, karena kondisi yang dibutuhkan juga lebih dari 2 kondisi, maka guanakanlah if dan else if , agar hasil outputnya sesuai dengan kebutuhan kita).

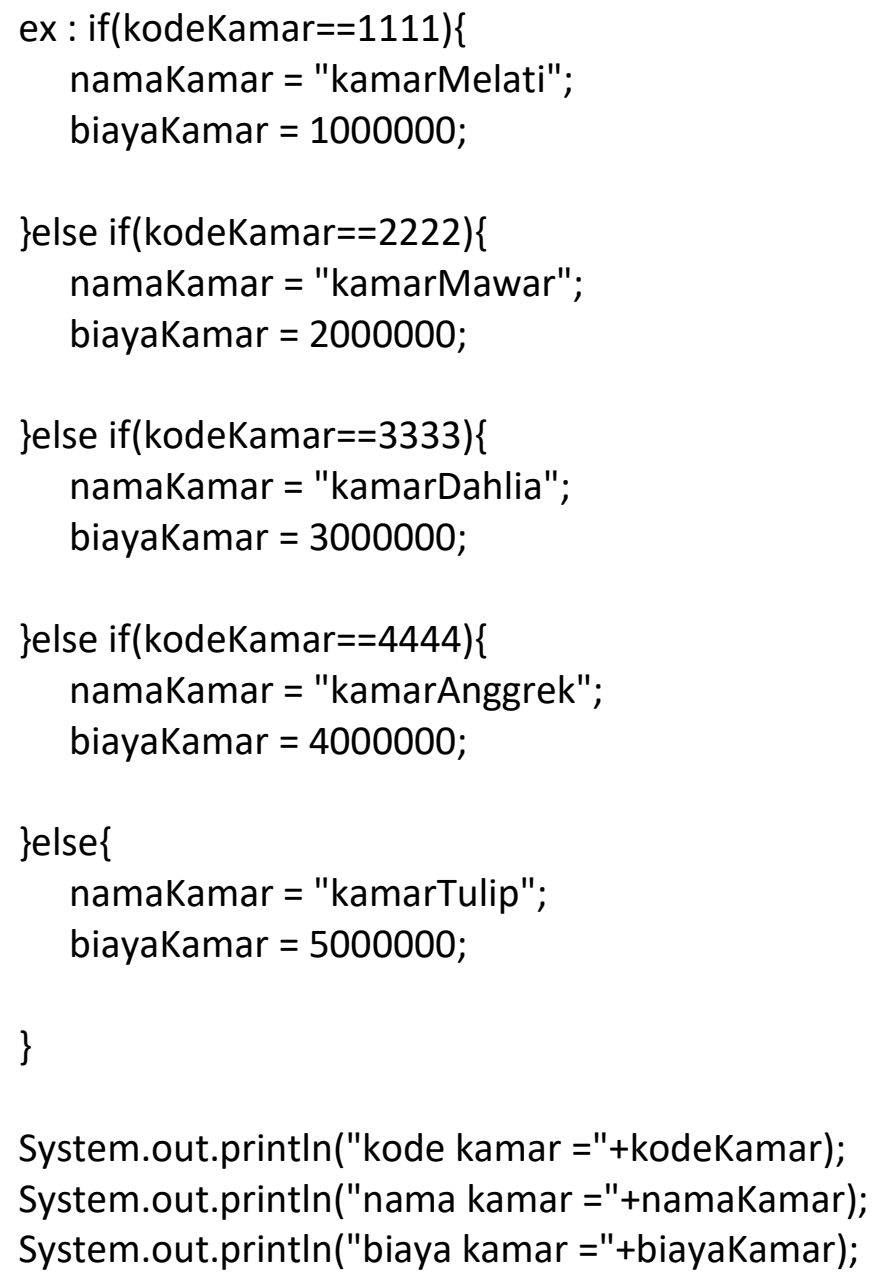

System.out.printIn("kode kamar ="+kodeKamar);

System. out.println("nama kamar ="+namaKamar);

System.out.println("biaya kamar ="+biayaKamar);

7. Lalu setelah codingan tabel 1 dan 2 selesai, maka kita codingkanlah lagi tabel 3 yang diatas. (Masih sama, karena kondisi yang dibutuhkan juga lebih dari 2 kondisi, maka guanakanlah if dan else if, agar hasil outputnya sesuai dengan kebutuhan kita).

ex : if(kodeDokter=="DK001")\{

namaDokter = "DR. Andi";

biayaPemeriksaan $=500000$;

\}else if(kodeDokter=="DK002")\{

namaDokter = "DR. Joko";

biayaPemeriksaan $=400000$;

\}else if(kodeDokter=="DK003")\{

namaDokter = "DR. Karni";

biayaPemeriksaan $=300000$;

\}else if(kodeDokter=="DK004")\{

namaDokter = "DR. Amin";

biayaPemeriksaan $=200000$;

\}else\{

namaDokter = "DR. Udin";

biayaPemeriksaan = 100000;

\}

System.out.printIn("kode dokter ="+kodeDokter);

System.out.printIn("nama dokter ="+namaDokter);

System.out.printIn("biaya pemeriksaan ="+biayaPemeriksaan); 
8. Lalu setelah codingan tabel 1,2 dan 3 selesai, maka kita codingkanlah lagi tabel 4 yang diatas. (Masih sama, karena kondisi yang dibutuhkan juga lebih dari 2 kondisi, maka guanakanlah if dan else if , agar hasil outputnya sesuai dengan kebutuhan kita).

ex : if(lamaMenginap $>=10)\{$ diskon $=0.5 *$ biayaKamar;

\}else if(lamaMenginap $>=8)\{$ diskon $=0.4$ *biayaKamar;

\}else if(lamaMenginap $>=6)\{$ diskon $=0.3^{*}$ biayaKamar;

\}else if(lamaMenginap $>=4)\{$ diskon $=0.2 *$ biayaKamar;

\}else\{ diskon $=0.1$ biayaKamar; \}

System.out.printIn("lama menginap ="+lamaMenginap); System.out.print In("diskon ="+diskon);

9. Untuk mengakhiri codingan yang telah kita buat pada tabel ke-1,2,3 dan 4 diatas. Langkah selanjutnya adalah memasukkan code dibawah berikut untuk menentukan: totalBayar = biayaDaftar + biayaKamar + biayaPemeriksaan - diskon;

System.out.printIn("total bayar ="+totalBayar); 


\section{FLOWCHART PROGRAM}

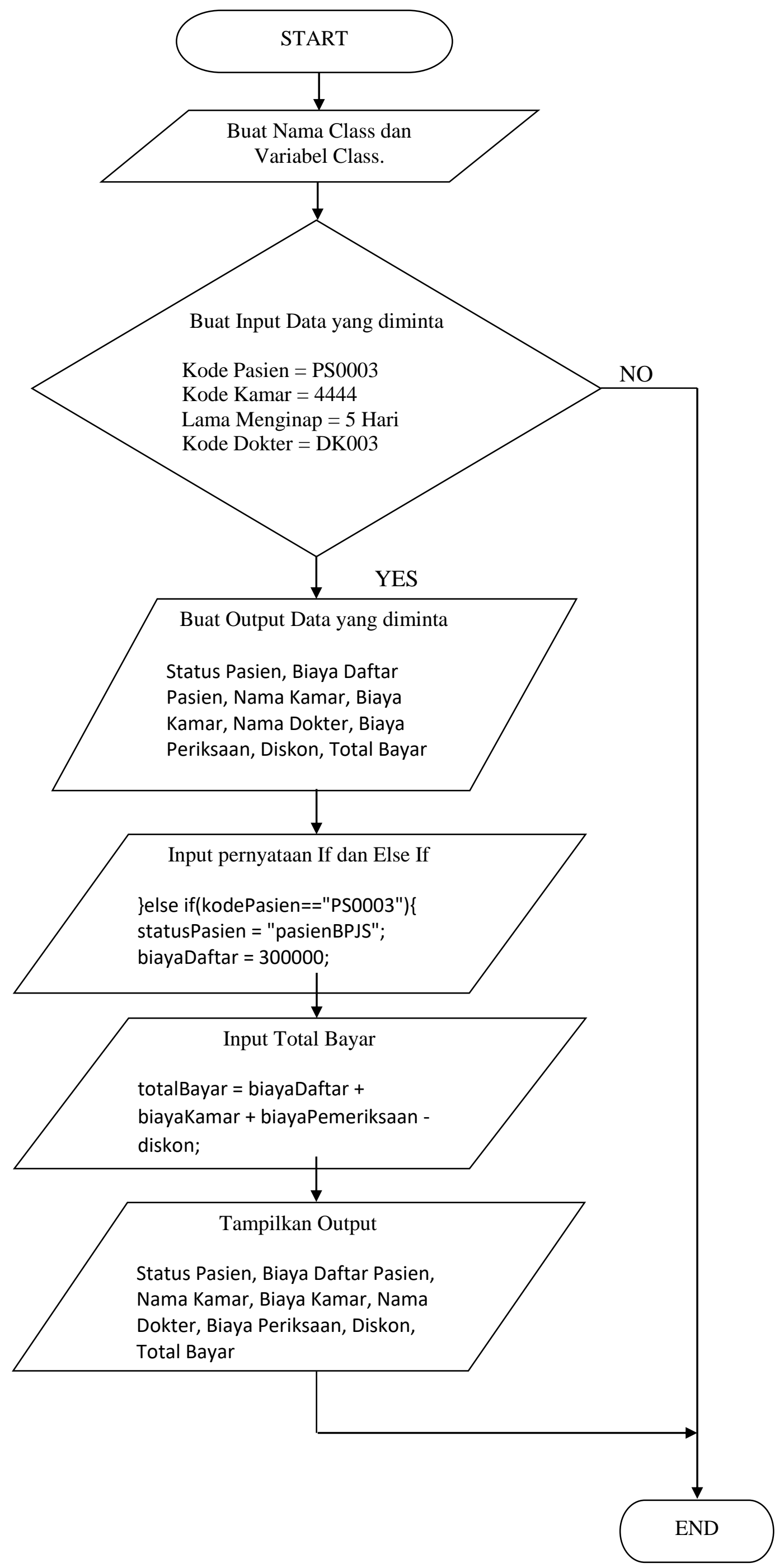




\section{REFERENSI :}

Endra, R. Y. (2019, October 29). Belajar Mudah Algoritma dan Pemograman Java. Retrieved from osf.io/v7yfn

Endra, R. Y. (2019, October 29). Internet of Things. Retrieved from osf.io/4h8sf 